\title{
Bilateral neuralgic amyotrophy complicating Weil's disease
}

\author{
W. J. K. Cumming* \\ M.B., M.R.C.P. \\ D. C. ThRUSH* $\dagger$ \\ M.D., M.R.C.P. \\ D. H. KENWARD $\ddagger$ \\ M.D., M.R.C.P.
}

Department of Neurology, Middlesbrough General Hospital, Ayresome Green Lane, Middlesbrough, and $\ddagger$ North Ormesby Hospital, North Ormesby, Middlesbrough

\begin{abstract}
Summary
The case of a patient with leptospirosis (treated with trimethoprim) with late neurological complications manifesting as a bilateral plexus syndrome is described. The probable reasons for the continued weakness, in this patient, of the muscles supplied by the anterior interosseus nerve, despite improvement in the proximal muscles, are briefly discussed.
\end{abstract}

\section{Introduction}

Neurological complications are rarely seen during the course of Weil's disease (Edwards and Domm, 1960). The authors now report the occurrence of bilateral asymmetric neuralgic amyotrophy in a patient suffering from leptospirosis.

\section{Case report}

A 48-year-old farmer was admitted to hospital with a 2-day history of malaise, headache and fever. A diagnosis of probable viral infection was made and he was treated with trimethoprim (Septrin) tablets 2 twice/day. Three days following admission he became jaundiced (bilirubin $240 \mu \mathrm{mol} / \mathrm{l}$ ) and developed renal failure (urea $21.6 \mathrm{mmol} / \mathrm{l}$; creatinine $957 \mu \mathrm{mol} / \mathrm{l}$ ). He was treated with haemodialysis which was continued to the twelth day and during this period his liver function improved (bilirubin $90 \mu \mathrm{mol} / \mathrm{l}$ ) simultaneously with the improvement in his renal function. A diagnosis of Leptospira infection with the strain canicola was made on the basis of Leptospira titres (gross titre 1/40 icterohaemorrhagiae 1/30, canicola 1/100).

On the fourteenth day of his illness, he developed pain around the left shoulder which became increasingly severe over a $24 \mathrm{hr}$ period and lasted for $72 \mathrm{hr}$. Similar pain was experienced on the right, but of lesser degree. As the pain subsided, the patient noticed progressive weakness of his shoulder girdle musculature, more marked on the left. Over the ensuing seven days the weakness in the left arm

$\dagger$ Present address: Department of Neurology, Freedom Fields Hospital, Plymouth. spread to involve the distal musculature. Neuro logical examination on the twenty-first day of his. illness showed severe weakness of the left supra and infra spinatus muscles with deltoid, biceps, brachioe radialis, triceps and distal musculature being MRg Grade 2 (MRC, 1976) at best.

On the right side there was marked weakness (MRC Grade 3) of the supra and infra spinati and deltoid and mild weakness (MRC Grade 4) of thछ biceps, brachioradialis and triceps. All the deep tendon reflexes in the upper limbs were absent, excepo the right triceps; the remainder of the neurologicas examination was normal.

\section{Electrophysiological studies}

These are summarized in Table 1 and show lateral motor involvement.

The patient was re-examined 6 months later afte the onset of his neurological illness. At that time hik right-sided muscles had completely recovered and the proximal musculature on the left had improve $\vec{\Phi}$ to MRC Grade 4. There was still marked distaP weakness with an anterior interosseus nerve palsy.

\section{Discussion}

Neurological complications of leptospirosis falf into two main groups:

(a) Early: A polyradiculo-neuropathy which. occurs between the third and eighth days. Motor and sensory signs are present equally and the lower limbs are predominantly affected. Recovery occurs within 6 months.

(b) Late: Mono-, or polyneuropathy, occurring? 20-30 days after the onset of the disease, the majority of patients presenting with lower facial palsy Peripheral nerves are involved, with motor an sensory signs being present equally.

This patient falls into the latter category of late complications; however, the occurrence of a bilaterab plexus syndrome has not been previously described

The pathological basis of neuralgic amyotrophy? still awaits clarification. A wide range of precipitating factors have been described, including infection 
TABle 1.

\begin{tabular}{lllrrr}
\hline Nerve & Motor/sensory & \multicolumn{1}{c}{ Parameter } & $\begin{array}{c}\text { November } \\
1976\end{array}$ & $\begin{array}{r}\text { April } \\
1977\end{array}$ & $\begin{array}{c}\text { Control } \\
\text { values }\end{array}$ \\
\hline Median & Motor & Conduction velocity $\mathrm{m} / \mathrm{sec}$ & $52 \cdot 0$ & $51 \cdot 0$ & 58 \\
& & Terminal latency & $4 \cdot 0$ & $3 \cdot 8$ & $2 \cdot 7 \pm 0 \cdot 5$ \\
\multirow{3}{*}{ Ulnar } & Motor & Conduction velocity $\mathrm{m} / \mathrm{sec}$ & $53 \cdot 0$ & $53 \cdot 0$ & $57 \pm 8 \cdot 4$ \\
& & Terminal latency & $2 \cdot 8$ & $2 \cdot 9$ & $3 \cdot 1 \pm 1 \cdot 1$ \\
& Sensory & Amplitude $\mu \mathrm{V}$ & $12 \cdot 0$ & $12 \cdot 0$ & $12 \cdot 6 \pm 2 \cdot 0$
\end{tabular}

Latencies in msec from Erb's point:

\begin{tabular}{|c|c|c|c|c|c|}
\hline Muscle & \multicolumn{2}{|c|}{ November 1976} & \multicolumn{2}{|c|}{ April 1977} & Normal controls \\
\hline $\begin{array}{l}\text { Deltoid } \\
\text { Biceps } \\
\text { Triceps }\end{array}$ & $\begin{array}{l}\text { R } \\
5 \cdot 0 \\
\text { N.R. } \\
5 \cdot 9\end{array}$ & $\begin{array}{l}\text { L } \\
\text { N.R. } \\
\text { N.R. } \\
6.0\end{array}$ & $\begin{array}{l}\text { R } \\
4 \cdot 8 \\
9 \cdot 2 \\
\text { N.T. }\end{array}$ & $\begin{array}{c}\text { L } \\
\text { N.R. } \\
\text { N.R. } \\
\text { N.T. }\end{array}$ & $\begin{array}{c}3.9 \pm 0.2 \\
4 \cdot 5 \pm 0.3 \\
-\end{array}$ \\
\hline
\end{tabular}

N.R. Not recordable, N.T. Not tested.

trauma, surgical operation and immunization. Recurrence may occur and some familial cases are seen (Bradley et al., 1975).

The rate of recovery is roughly proportional to the distance of the affected muscle from the brachial plexus. Thus it is not surprising, in this patient, that the muscles supplied by the anterior interosseus nerve have remained weak, despite improvement in the proximal muscles.

\section{References}

Bradley, W.G., Madrid, R., Thrush, D.C. \& Campbell, M.J. (1975) Recurrent brachial plexus neuropathy. Brain, 98, 381.

Edwards, G.A. \& Domm, B.M. (1960) Human leptospirosis Medicine. Baltimore, 39, 117.

Medical Research Council (1976) Aids to the Examination of the Peripheral Nervous System. MRC Memorandum No. 45. H.M. Stationery Office, London. 